OPEN ACCESS

Edited by:

Yves Renaudineau,

Université de Bretagne Occidentale,

France

Reviewed by:

Matthias Hauptmann,

Research Center Borstel, Germany Christian Furlan Freguia,

Synthetic Biologics, Inc.,

United States

*Correspondence:

Klara Klimesova

klimesov@biomed.cas.cz

Specialty section:

This article was submitted to

Microbial Immunology,

a section of the journal

Frontiers in Microbiology

Received: 28 September 2017

Accepted: 05 April 2018

Published: 20 April 2018

Citation:

Klimesova K, Jiraskova Zakostelska Z and Tlaskalova-Hogenova H (2018) Oral Bacterial and Fungal Microbiome Impacts Colorectal Carcinogenesis.

Front. Microbiol. 9:774.

doi: 10.3389/fmicb.2018.00774

\section{Oral Bacterial and Fungal Microbiome Impacts Colorectal Carcinogenesis}

\author{
Klara Klimesova*, Zuzana Jiraskova Zakostelska and Helena Tlaskalova-Hogenova
}

Laboratory of Cellular and Molecular Immunology, Institute of Microbiology of the CAS, Prague, Czechia

Host's physiology is significantly influenced by microbiota colonizing the epithelial surfaces. Complex microbial communities contribute to proper mucosal barrier function, immune response, and prevention of pathogen invasion and have many other crucial functions. The oral cavity and large intestine are distant parts of the digestive tract, both heavily colonized by commensal microbiota. Nevertheless, they feature different proportions of major bacterial and fungal phyla, mostly due to distinct epithelial layers organization and different oxygen levels. A few obligate anaerobic strains inhabiting the oral cavity are involved in the pathogenesis of oral diseases. Interestingly, these microbiota components are also enriched in gut inflammatory and tumor tissue. An altered microbiota composition - dysbiosis - and formation of polymicrobial biofilms seem to play important roles in the development of oral diseases and colorectal cancer. In this review, we describe the differences in composition of commensal microbiota in the oral cavity and large intestine and the mechanisms by which microbiota affect the inflammatory and carcinogenic response of the host.

Keywords: microbiome, mycobiome, pathobiont, dysbiosis, biofilm, Fusobacterium, oral diseases

\section{INTRODUCTION}

Both the upper and lower parts of the human digestive tract harbor a complex ecosystem of bacteria, fungi, protozoa, and viruses, referred to as the microbiome. It begins to form even before birth, in the uterus, developing for another 2-3 years after birth to become a stable, fully functioning microbiome, until the physiological changes associated with senescence lead again to substantial shifts in its composition (Adlerberth and Wold, 2009; Aagaard et al., 2014; Maffei et al., 2017). The lower part of the digestive tract gets "inoculated" every day by about $10^{11}$ bacteria from the oral cavity and microbial species detected in the oral and fecal microbiota overlap in about $45 \%$ of tested individuals (Socransky and Haffajee, 2002; Segata et al., 2012). Moreover, via the blood stream, these oral bacteria can disseminate all over the body. Fungal microbiota can colonize the gut perorally as well, with some strains detected in the gut likely to be contaminants from the environment or food, rather than commensals (Trojanowska et al., 2010). The composition and function of the microbiome change along the digestive tract, from the oral cavity to the rectum. These differences have been previously described in detail (Arumugam et al., 2011; Human Microbiome Project Consortium, 2012) and will be briefly outlined below.

Collectively, the genes encoded by the microbial genomes outnumber the genes in the human genome about 100 -fold and this variation enables the commensal microbiota to use substrates indigestible by humans (Qin et al., 2010). Products of microbial metabolic activity include vitamins, 
short-chain fatty acids (SCFAs), and other compounds important for host cell metabolism and survival. Moreover, the host's physical interaction with or sensing of the microbial components is important for proper mucosal barrier function and mucosal immune system development and homeostasis. On the other hand, recent studies have shown that some commensal microbes can under certain conditions become pathogenic - so called pathobionts. Mechanisms include expression of virulence factors, such as adhesion molecules or proteases, or formation of a biofilm, and such activity can lead to disease initiation or progression. One such example is Escherichia coli, a large and diverse group of various bacterial serotypes. E. coli strains differ in their activities and biological roles: some of them are gut commensals and commercially available probiotics, others can be pathogens causing gastrointestinal and urinary infections or pathobionts associated with inflammatory bowel disease (IBD) and colorectal cancer (CRC).

The jury is still out on what triggers this transformation of commensals into pathobionts; it might be that a change in the gut microenvironment simply allows the microbes to interact with the host in an aberrant way. The gut microbiota composition and function can be influenced by various factors (Figure 1). For instance, many substances produced by the host and secreted into gut lumen, such as antibacterial peptides, secretory IgA, mucins, cytokines, or neuromediators, can shape the microbial community. Their production depends on host gene polymorphisms and their expression in host cells is often driven by microbial stimulation, creating a positive feedback loop. Mechanisms responsible for cancer development include some of these factors but others are still under scientific investigation.

Colorectal cancer is the most prevalent type of cancer in developed and developing countries (Ferlay et al., 2015).

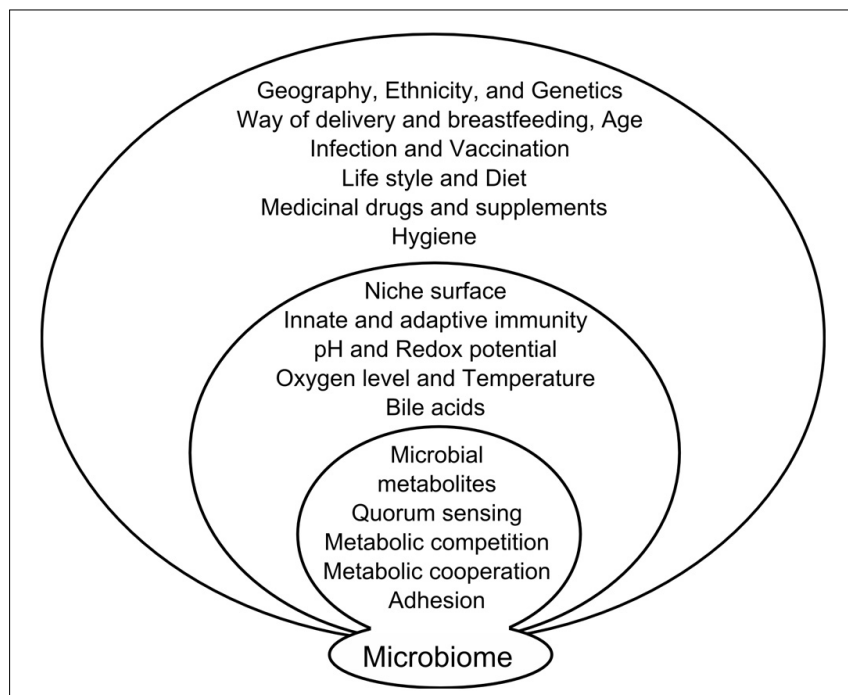

FIGURE 1 | Factors influencing microbiome composition. Microbiome composition is influenced on several levels by factors from external environment, factors resulting from the interaction of microbiota with the host and mutual interaction of the microbiome components.
Only a small percentage of colorectal cancers is hereditary or associated with certain predisposing conditions, such as chronic intestinal inflammation in IBD patients. The majority of cases thus represents sporadic cancers (85-95\%) and can be, to some extent, influenced by environmental factors. The composition and metabolic activity of gut microbiota may be therefore a crucial component of CRC pathogenesis (Arthur and Jobin, 2011).

Findings of significant colonization of cancer tissue by microbes usually found in the oral cavity have sparked a debate about a possible involvement of oral microbiota in CRC development process. Many experimental studies have provided evidence for a significant role of microbiota in carcinogenesis. However, due to the complexity of microbial cooperation and interaction with the host, all the underlying mechanisms are yet to be elucidated. Here, we review the properties of bacterial and fungal populations inhabiting the oral cavity and gut, with emphasis on their association with CRC pathogenesis.

\section{ORAL MICROBIOTA}

The microorganisms found in the human oral cavity are referred to as the human oral microbiome and play a crucial role in maintenance of homeostasis in the mouth. Each individual's oral microbiome consists of a distinct set of microorganisms. The mouth supports one of the most diverse microbial communities compared with other body sites, such as the skin and vagina, due to its heterogeneity and the interrelationships between the different anatomic structures (Wade, 2013). The constantly humid environment of the oral cavity is maintained at a relatively stable temperature $\left(34-36^{\circ} \mathrm{C}\right)$, while the varying $\mathrm{pH}$ levels and different types of diet contribute to the substantial microbiome variability (Marcotte and Lavoie, 1998). Habitats of the oral cavity are represented by both hard (teeth) and soft tissues (cheek, tongue, lip, gingival sulcus, attached gingiva, hard and soft palate) and their interface (subgingival and supragingival margins, and gingival crevices around teeth). The contiguous extensions of the oral cavity, including the tonsils, pharynx, esophagus, Eustachian tube, middle ear, trachea, lungs, nasal passages, and sinuses, are also colonized by the oral microbiome but the majority of studies describing the oral microbiome composition include only samples from the oral cavity (Mager et al., 2003; Aas et al., 2005). Moreover, all these structures are constantly moistened by two physiological fluids, saliva and the gingival crevicular fluid, which help to maintain the oral microbiome homeostasis by providing water, nutrients, antibodies, and antimicrobial and adherence factors (Marcotte and Lavoie, 1998).

The National Institute of Health's Human Microbiome Project identified the most dominant phyla that account for over $95 \%$ of the entire oral microbiome: Firmicutes, with the Streptococcus as a dominant genus, Bacteroidetes, strongly represented by Prevotella and Proteobacteria, with highly abundant Haemophilus, Fusobacteria, and Actinobacteria (Human Microbiome Project Consortium, 2012; Huse et al., 2012; Zhou et al., 2013). The oral cavity displays greater alphadiversity (species richness) than either the skin or vagina, 
characterized by uniform abundance of the major species (Huse et al., 2012). On the other hand, beta-diversity, i.e., differences in microbiome composition in oral sites among various subjects, is the lowest compared to the other body sites (Huse et al., 2012). Within the oral cavity, the highest microbiota richness has been found in the gingival plaque and in saliva, whereas the lowest richness has been described in keratinized gingiva (Huse et al., 2012; Zhou et al., 2013). It seems that saliva contributes unevenly to the microbial composition of different sites in the oral cavity. Due to its rapid turnover and low levels of nutrients, saliva itself does not contain a stable indigenous biota and owes its high alphadiversity primarily to bacteria shed from other oral tissues (Mager et al., 2003). In general, species like Streptococcus, Gemmella, Granulicatella, Veillonella, and Fusobacterium can be detected across almost all oral sites, while others are represented only at one or two oral sites, e.g., Prevotella, Bacteroides, Corynebacterium, Pasteurella, and Neisseria (Huse et al., 2012). Bacterial species in the oral cavity find the most stable environment at the supragingival or subgingival tooth surfaces. These non-shedding surfaces are covered by persisting biofilms composed mainly by Streptococcus and Actinomyces, representing the earliest colonizers of teeth, and Veillonella (Socransky and Haffajee, 2005; Teles et al., 2013). Taken together, although most microbial species found in the oral cavity differ in their abundance, their representation and activity is more important.

\section{ORAL MICROBIOME AND ORAL DISEASES}

A considerable number of oral conditions, including caries and periodontal diseases, endodontic infections, alveolar osteitis, and tonsillitis is connected to detrimental alteration in microbiota composition - a dysbiosis (Costalonga and Herzberg, 2014; Proctor and Relman, 2017). For instance, periodontal inflammation is directly induced by microbes colonizing the biofilm in the gingival sulcus and, at later stages, in the periodontal pockets. These oral biofilms contain 100s of different bacterial species in one periodontal lesion, with composition different from that in healthy periodontium (Socransky and Haffajee, 2005; Teles et al., 2013). Initially, the plaque forms only supragingivally but if it is not removed properly, after a few days it spreads below the gingival margin and into the sulcus. There, after the depletion of oxygen, a new environment is established, where anaerobic bacteria can flourish. Three most destructive anaerobic bacteria involved in severe periodontal disease, the so called "red complex," include Treponema denticola, Tannerella forsythia and Porphyromonas gingivalis (Socransky et al., 1998). Aggressive form of periodontitis is further associated with Aggregatibacter actinomycetemcomitans (Slots, 1976). The immunopathological mechanisms in periodontal disease development and course have been recently thoroughly reviewed by Hajishengallis and Korostoff (2017). Recurrent aphthous stomatitis is also connected to changes in microbiota composition; decreased abundance of Streptococcus salivarius and increased Acinetobacter johnsonii have been linked to the disease incidence (Bankvall et al., 2014; Kim et al., 2016).

As mentioned previously, the human microbiome diversity is not limited only to bacteria but also includes fungal species. However, this oral mycobiome have been only recently characterized and despite its potential great scientific importance, we found only few studies where its composition was analyzed using high throughput sequencing. Ghannoum et al. (2010) reported that healthy oral mycobiota contained 74 culturable and 11 non-culturable fungal genera. They have revealed great interindividual variation and proposed that the presence of certain fungal isolates (e.g., Candida, Aspergillus, Cryptococcus) probably predisposes the host to opportunistic infections. Malassezia species, previously described as commensals and pathogens of the skin and lungs, have been recently found as predominant commensals in saliva (Saunders et al., 2012; Dupuy et al., 2014). Many other species are likely still waiting to be discovered and were not detected earlier because of their special growth requirements (Nagano et al., 2010). The first evidence of interactions among members of the oral mycobiome community and their association with specific disease came from a study characterizing the oral mycobiome in HIV patients (Mukherjee et al., 2014). The authors found that a decrease in abundance of an indigenous fungus Pichia in uninfected individuals went hand in hand with an increase in abundance of Candida, suggesting an antagonistic relationship. Pichia inhibits Candida by different mechanisms, including competition for nutrients and secretion of factors that disrupt the latter's ability to adhere, germinate, and form biofilms. Moreover, they found a negative correlation between Candida and Campylobacter in HIV-infected subjects, whereas in healthy subjects, no correlation between Candida and bacterial species was detected (Mukherjee et al., 2014). Recently, Peters et al. (2017) published a pilot study describing oral mycobiome in healthy subjects and those with periodontal disease. In diseased subjects, they found a slightly increased abundance of Candida genera which is in agreement with previous culture-based studies (Urzúa et al., 2008; Canabarro et al., 2013). Despite those first studies aiming for a deeper understanding of the factors affecting the oral mycobiota composition, information about their direct and indirect effects on human health and the interactions between the fungi and bacteria is still lacking.

The involvement of microbiota in the pathogenesis of oral diseases has been documented using gnotobiotic rat and mouse models of human diseases. Germ-free animals can be obtained by delivering the young by sterile Cesarean section and raising them aseptically in isolators for germ-free rearing. Such animals made it possible to study the effects of commensal bacteria in the oral cavity, including the effects on periodontal tissues. In germ-free mice and rats, it was demonstrated that periodontal disease and caries, similarly to other human inflammatory diseases, cannot be experimentally induced in the absence of microbiota (Heijl et al., 1980; Tlaskalova-Hogenova et al., 2004). Experimental animal models (e.g., the gavage model of periodontal disease) and in vitro studies revealed that certain components of oral microbiota, mainly $P$. gingivalis, play a crucial role in the innate host defense of periodontium and that dysregulation of the immune response 
in the presence of oral microbiota leads to inflammation and alveolar bone loss (Ivanyi et al., 1991; Darveau et al., 2012; Papadopoulos et al., 2013). The mechanisms by which microbiota triggers the pathological changes are not yet fully understood, however, new approaches promise to shed light on the role of oral microbiota (Kinane et al., 2017; Pitts et al., 2017).

\section{ORAL MICROBIOME AND EXTRA-ORAL DISEASES}

Dysbiosis of the oral microbiome is not only connected with the incidence and maintenance of oral diseases, but has been also implicated in the pathogenesis of autoimmune, inflammatory, and neoplastic diseases (e.g., heart disease, respiratory illnesses, psoriasis, psoriatic arthritis, and carcinogenesis at various sites) (He et al., 2015; Roberts and Darveau, 2015; Egeberg et al., 2017; Ungprasert et al., 2017). Moreover, oral microbiota seems to affect the outcome of pathological pregnancy (preterm birth, abortions, etc.); reviewed by Cobb et al. (2017). Periodontal bacterial DNA has been found in atherosclerotic plaques of patients suffering from ischemic heart disease and atherosclerosis (Ford et al., 2005, 2006). Bacteria may initiate or exacerbate atherosclerotic processes through activation of innate immunity, direct involvement of mediators activated by dental plaque antigens in atheroma processes, or involvement of cytokines and heat shock proteins from dental plaque bacteria. There might be also genetic predisposing factors influencing both diseases (Bartova et al., 2014). Furthermore, patients with rheumatoid arthritis have a higher prevalence of periodontal disease and vice versa (Kasser et al., 1997; Greenwald and Kirkwood, 1999). Bacterial DNA has been detected in the synovial fluid of patients with rheumatoid arthritis or with failed prosthetic joints, suggesting the possibility of infection translocating from the periodontal tissue to the synovium (Temoin et al., 2012). The oral microbiome is not confined to spreading to contiguous epithelial surfaces, but can also be carried by the bloodstream to distant body sites, such as the heart, skin, and joints. Oral microbiota enters the bloodstream during routine daily activities like tooth brushing or through inflamed tissue in the course of oral diseases (Tomas et al., 2012). The mechanisms of dissemination of potentially pathogenic microbes from the oral cavity through bloodstream are still not clear. Potential connection with systemic low-grade inflammation has been also discussed (Potgieter et al., 2015).

In most conditions discussed so far, no particular microbe or microbes have been described as a causative agent. However, thanks to advances in molecular methods, presence of Fusobacteria and other oral bacteria has been recently demonstrated in various systemic pathological conditions, including digestive diseases, such as appendicitis, IBD and CRC. Moreover, a correlation of the presence of oral bacteria $P$. gingivalis and A. actinomycetemcomitans with an increased risk of developing pancreatic cancer has been observed in a large group of subjects with incident primary pancreatic adenocarcinoma (Fan et al., 2016). Several recent studies have repeatedly confirmed the presence of oral bacteria in the gut, especially in association with CRC mucosa. For instance, Nakatsu et al. (2015) have shown that a substantial part of gut microbiome associated with CRC is composed of oral bacteria and Fusobacterium in particular. Momen-Heravi et al. (2017) also proposed a role of oral bacteria in CRC development. They conducted a retrospective study in a huge cohort of women and discovered an association of periodontal disease and tooth loss with CRC morbidity and found that women with less than 17 teeth may be at a greater risk of incident CRC (Momen-Heravi et al., 2017).

\section{ORAL MICROBIOTA AND COLORECTAL CARCINOGENESIS}

It is generally accepted that the gut microbiome plays a role in CRC development. Experimental proof of gut microbiota involvement in CRC development came from gnotobiotic animal models (Reddy et al., 1975; Vannucci et al., 2008; Arthur and Jobin, 2011; Klimesova et al., 2013; Tlaskalova-Hogenova et al., 2014). Recent studies using next generation sequencing and polymerase chain reaction have shown that Fusobacterium nucleatum is frequently detected in stool and biopsy samples from CRC patients (Castellarin et al., 2012; Kostic et al., 2012; Flanagan et al., 2014). These adhesive, anaerobic Gram-negative bacteria attract considerable attention in search for possible mechanisms behind their inflammatory and tumorigenic activity. Some of the features of $F$. nucleatum and the host responses are already known: $F$. nucleatum modulates E-cadherin/ $\beta$-catenin signaling via its FadA adhesin/invasin - a key virulence factor, and alters macrophage infiltration and methylation of the CDKN2A promoter in CRC lesions (Rubinstein et al., 2013; Park et al., 2017). It seems that Fap2 Gal-GalNAc lectin of F. nucleatum could be responsible for its tendency to bind to tumor cells displaying Gal-GalNAc moieties (Abed et al., 2016). Moreover, several other virulence proteins that might participate in inflammatory and neoplastic processes have been described in F. nucleatum, using proteomic approaches (Zanzoni et al., 2017). In the host, $F$. nucleatum activates numerous immune responses including human $\beta$-defensin production, lymphocyte apoptosis, and production of proinflammatory cytokines interleukin (IL)-6, IL-8, and TNF- $\alpha$ (Han, 2015).

The fact that Fusobacterium is highly abundant in patients with CRC led to various efforts to apply this finding for clinical purposes. For instance, a highly sensitive DNA test for $F$. nucleatum has been developed for screening and prognosis of CRC in Japan (Yamaoka et al., 2017). Fusobacterium has been recently shown to predict the aggressiveness and recurrence of CRC and its resistance to chemotherapy. It seems to be modifying the innate immune signaling and regulating specific microRNAs that activate the autophagy pathway (Yu et al., 2017). In connection with this finding, an argument has been made to use anti-F. nucleatum therapy together with chemotherapy.

The dietary patterns leading to CRC development have been studied for several decades. Recently, it was shown that individuals consuming a western-type diet have a higher incidence of Fusobacterium-associated CRC and that diets rich 
in whole grains and dietary fiber are associated with a lower risk of F. nucleatum-positive CRC (Mehta et al., 2017).

Despite the clinical observation of increased abundance of Fusobacterium in patients with CRC (especially in chemoresistant forms of CRC), direct clinical evidence of a causal relationship is still lacking. A recent study revealed that fusobacterial abundance is not significantly increased in fecal samples of patients with adenomas, implying that the relationship between Fusobacterium and CRC might not be causal after all. Amitay et al. (2017) hypothesize that Fusobacterium is more likely just a passenger colonizing the favorable niche in a gut with CRC, rather than the driver of cancer development. Experimental evidence of its potential causal role is based on in vitro and animal models of CRC. For instance, it has been shown that F. nucleatum potentiates tumorigenesis in monoassociated $\mathrm{Apc}^{\mathrm{min} /+}$ mice (Kostic et al., 2013).

While Fusobacterium is the most studied periodontal microbe in connection to CRC, other components of the oral microbiome may also be implicated in CRC pathogenesis and will be discussed later (Table 1).

\section{GUT MICROBIOME, METABOLIC ACTIVITY, AND COLON CARCINOGENESIS}

Thanks to advances in high-throughput sequencing and metabolomic approaches, we have a growing understanding of the composition and metabolic activity of the microbiome associated with colorectal carcinogenesis. Studies have shown that gut microbiome differs between healthy individuals and adenoma/carcinoma patients and that microbial diversity in cancer is reduced (Peters et al., 2016). The adenoma-carcinoma sequence in CRC development suggests an associated continuous alteration of the resident microbiome, which is supported by recent research. Analyses of fecal microbiome composition in patients with adenoma have shown increased normalized abundance of genera such as Actinomyces, Corynebacterium, Porphyromonas, Mogibacterium, and Haemophilus when compared with healthy individuals (Peters et al., 2016; Hale et al., 2017). Cancer patients have shown further differences in fecal microbiota composition, with a marked enrichment of Ruminococcus, Oscillibacter, and Roseburia, and Porphyromonas, Fusobacterium, and Peptostreptococcus, i.e., strains associated with periodontal disease (Table 1) (Shen et al., 2010; Flemer et al., 2017; Liang et al., 2017).

Moreover, fecal samples reflect the microbial colonization of tissues, as biopsies from adenomas and carcinomas have been similarly different from healthy mucosa (Flemer et al., 2017). The findings that there is very little difference in microbiota composition between diseased and adjacent unaffected tissue suggest that the microbiome undergoes a systemic change, affecting the whole community (Lu et al., 2016; Flemer et al., 2017). Such results support the driver/passenger model, the idea that certain strains disturb the microbial community and the mucosal microenvironment (drivers) and such changes lead to subsequent colonization by pathobionts and pathogens
TABLE 1 | Oral microbiota and its possible mechanisms related to tumorigenesis.

\begin{tabular}{|c|c|c|}
\hline Microbial genera & Activity & Reference \\
\hline Streptococcus & $\begin{array}{l}\text { Adhesion, } \\
\text { co-aggregation } \\
\text { Biofilm formation } \\
\text { Protease activity } \\
\text { Hemolytic activity }\end{array}$ & $\begin{array}{l}\text { da Silva et al., } 2014 \\
\text { Diaz et al., } 2012 \\
\text { Kilian et al., } 1988 \\
\text { Wong et al., } 2016\end{array}$ \\
\hline Peptostreptococcus & $\begin{array}{l}\text { Biofilm formation } \\
\text { Antiapoptotic effect } \\
\text { Hydrogen sulfide } \\
\text { production }\end{array}$ & $\begin{array}{l}\text { Tsoi et al., } 2017 \\
\text { Persson et al., } 1990\end{array}$ \\
\hline Parvimonas & $\begin{array}{l}\text { Biofilm formation } \\
\text { Hemolytic activity } \\
\text { Proinflammatory } \\
\text { stimulation } \\
\text { Hydrogen sulfide } \\
\text { production }\end{array}$ & $\begin{array}{l}\text { Wong et al., } 2016 \\
\text { Marchesan et al., } 2016 \\
\text { Carlsson et al., } 1993\end{array}$ \\
\hline Dialister & $\begin{array}{l}\text { Biofilm formation } \\
\text { Proinflammatory } \\
\text { stimulation }\end{array}$ & $\begin{array}{l}\text { da Silva et al., } 2014 \\
\text { Sousa et al., } 2014\end{array}$ \\
\hline Mogibacterium & Biofilm formation & Casarin et al., 2012 \\
\hline Fusobacterium & $\begin{array}{l}\text { Adhesion } \\
\text { Proinflammatory } \\
\text { stimulation } \\
\text { Immune evasion } \\
\text { Hemolytic activity } \\
\text { Hydrogen sulfide } \\
\text { production }\end{array}$ & $\begin{array}{l}\text { Kostic et al., } 2013 \\
\text { Rubinstein et al., } 2013 \\
\text { Wong et al., } 2016 \\
\text { Claesson et al., } 1990\end{array}$ \\
\hline Porphyromonas & $\begin{array}{l}\text { Biofilm formation } \\
\text { Immune evasion } \\
\text { Antiapoptotic effect } \\
\text { Protease activity } \\
\text { Hemolytic activity } \\
\text { Hydrogen sulfide } \\
\text { production } \\
\text { Proinflammatory } \\
\text { stimulation }\end{array}$ & $\begin{array}{l}\text { Inaba et al., } 2013 \\
\text { Mao et al., } 2007 \\
\text { Potempa et al., } 2003 \\
\text { Wong et al., } 2016 \\
\text { Persson et al., } 1990 \\
\text { Sousa et al., } 2014\end{array}$ \\
\hline Campylobacter & $\begin{array}{l}\text { Hemolytic activity } \\
\text { Proinflammatory } \\
\text { stimulation }\end{array}$ & $\begin{array}{l}\text { Wong et al., } 2016 \\
\text { Marchesan et al., } 2016\end{array}$ \\
\hline Candida & $\begin{array}{l}\text { Adhesion } \\
\text { Biofilm formation } \\
\text { Protease activity } \\
\text { Hemolytic activity }\end{array}$ & $\begin{array}{l}\text { Diaz et al., } 2012 \\
\text { Gomes et al., } 2017\end{array}$ \\
\hline
\end{tabular}

(passengers) (Tjalsma et al., 2012). Both the drivers and the passengers modulate the local microenvironment through different means, such as virulence factors or metabolic activity. Drivers thus promote cancer initiation at the very beginning by their involvement in DNA damage, cell cycle regulation, apoptosis and epithelium proliferation, whereas passengers more likely promote tumorigenesis via chronic proinflammatory stimulation and direct tissue damage.

Drivers often include microbes that produce genotoxic substances, which damage DNA, or cyclomodulins, which can modulate the epithelial cell cycle - recently thoroughly reviewed by Gagniere et al. (2016) and El-Aouar et al. (2017). Bacteroides fragilis and Enterococcus faecalis have the potential to damage epithelial cells and initiate cancer formation by producing the enterotoxin fragilysin and reactive oxygen species, such as superoxide, respectively (Huycke et al., 2002; Toprak 
et al., 2006). Several studies confirmed that E. coli strains encoding the genotoxic polyketide synthase (pks) island are associated with inflamed gut mucosa and CRC (Swidsinski et al., 1998; Nougayrede et al., 2006; Arthur et al., 2012; Raisch et al., 2014). Interestingly, members of the family Enterobacteriaceae, including E. coli, can produce several types of genotoxins or cyclomodulins. Cytotoxic necrotizing factors and cycle-inhibiting factor modulate the cell cycle and can lead to uncontrolled proliferation or cell cycle arrest, respectively (Taieb et al., 2006; Miraglia et al., 2007). Cytolethal distending toxins, similarly to pks, induce DNA double-strand breaks and apoptosis, but can also promote proinflammatory cytokine production in the host (Blazkova et al., 2010). In summary, the interplay of these factors with gut epithelium and immune cells can promote low-grade inflammation and cancer initiation. Moreover, we can assume that these molecules represent just the tip of the iceberg of as yet unknown microbial products of gut commensals with the potential to harm the gut epithelium.

Mycobiome, i.e., the fungal microbiome, forms an integral part of the gut microbial community, although it is much less investigated then the bacterial part. The most common genera residing in a healthy gut are Candida, Saccharomyces, and Cladosporium (Hoffmann et al., 2013). However, some non-commensal transient fungi, acquired with food or from the environment, can be also found in fecal samples and may comprise potentially pathogenic species. Trojanowska et al. (2010) have shown that the gut is colonized also by the oral mycobiome, as they found a genetically identical Candida albicans strain in the mouth and colon of patients with IBD. Unfortunately, data about fungal colonization of the digestive tract in relation to neoplastic diseases are still sparse. A disruption of the bacterial and fungal community - dysbiosis, has been observed in individuals with IBD (Sokol et al., 2017), who are known to be at increased risk of CRC development. Interestingly, reduced richness and diversity has been detected not only in bacterial, but also in fungal microbiome (Chehoud et al., 2015; Liguori et al., 2016; Sokol et al., 2017). For instance, the Cystofilobasidiaceae family, Dioszegia genus and Candida glabrata have been found to be enriched in Crohn's disease compared with healthy mucosa (Liguori et al., 2016). The only published study on fungal microbiota in CRC deals with comparison of adenomas and adjacent tissues. Luan et al. (2015) have observed an increased abundance of Phoma and Candida genera and Candida tropicalis in adenomas. As pathobionts, these genera may be involved in cancer initiation, but further studies are needed to investigate whether they work as drivers or passengers.

Microbiome in the colon makes use of various catabolic and anabolic pathways, which enable it to utilize a broad spectrum of substrates that are not absorbed in the small intestine. These pathways interact with the metabolism of xenobiotics and influence micronutrient bioavailability, lead to the production of essential vitamins and degradation of fibers, and regulate the secretion of various molecules (Arthur and Jobin, 2011). Different dietary components can shift the microbiome composition. For instance, a diet high in resistant starch increases the abundance of bacteria metabolizing non-digestible polysaccharides (Walker et al., 2011). Indeed, increased abundance of Prevotella and Bacteroides has been observed in individuals preferring high sugar and high protein diet, respectively (Wu et al., 2011). Our digestion pathways lack the enzymes for the degradation of resistant starch and dietary fiber but the distal gut microbiome encodes about 81 different families of glycoside hydrolases (bacterial polysaccharidases, glycosidases), which are not present in the human genome (Gill et al., 2006). The microbiome thus significantly contributes to the utilization of starch, primary fiber, host-derived secretions (mucus glycans), sucrose, and monosaccharides.

Subsequent fermentation of depolymerized molecules leads to the production of SCFAs, mainly acetate, propionate, and butyrate. Compared with other microbiomes in gene libraries, the human gut microbiome is enriched with genes involved in the pathways generating SCFAs (Gill et al., 2006). Main producers of butyrate within the human gut microbiome are Faecalibacterium prausnitzii and Eubacterium rectale/Roseburia group (Louis et al., 2010). SCFAs provide one of the most important sources of energy, not only for intestinal epithelial cells but also for muscles, kidneys, heart, and brain. Their physiologic production impacts the metabolism and transport through the epithelium, as well as epithelial cell renewal and differentiation. Moreover, SCFAs greatly influence the immune system, colonic functions, and carcinogenesis. Butyrate production, for example, improves gut barrier integrity and reduces local oxidative stress and inflammation (Macfarlane and Macfarlane, 2012). Recently, Kaiko et al. (2016) came with an interesting finding that butyrate levels are much lower at the intestinal crypt base than in the lumen. Differentiated enterocytes use butyrate as an energy source and thus reduce its concentration along the way to the lamina propria, where a low concentration of butyrate keeps the epithelial progenitors proliferating and stimulates tolerogenic immune response (Kaiko et al., 2016). The role of SCFAs in cancerogenesis is not fully understood but their concentration could be an important factor.

On the other hand, degradation and fermentation of dietary proteins, peptides, and amino acids by bacteria generates byproducts, such as phenols, indoles, ammonia, amines, and hydrogen sulfite, all of which are to some extent harmful to the host, being co-carcinogens, mutagens, and cellular toxins (Macfarlane and Macfarlane, 2012). Moreover, hydrogen released as the end-product of fermentation is processed by methanogenic species of Archaea (e.g., Methanobrevibacter) to methane, which changes local conditions (redox potential and $\mathrm{pH}$ ) and thus regulates biochemical pathways (Gill et al., 2006).

Fungal metabolic activity includes the digestion of polysaccharides and fat residuals from the diet and host residuals, leading to the synthesis of a variety of secondary metabolites, which can substantially influence the surrounding prokaryotic and eukaryotic cells. An investigation of the relationship between fungal diversity and diet revealed a positive correlation of Candida with diet rich in saccharides and a negative correlation of Aspergillus with SCFAs (Hoffmann et al., 2013). Thus, close relationships between bacterial and fungal metabolic requirements can help structure the microbial community in the gut. For instance, antimicrobial treatment 
can significantly disrupt the ecological balance of microbiota throughout the digestive tract. Antibiotics eradicate some sensitive bacteria and their niche can be subsequently invaded by other bacteria or fungi (Huffnagle and Noverr, 2013). Interestingly, a nested case-control study has shown that bacterial or fungal outgrowth after multiple penicillin treatments slightly increases the risk of CRC development (Boursi et al., 2015). And, last but not least, consumption of food-associated mycotoxins - secondary metabolites of fungi, has been linked to carcinogenesis throughout the digestive tract (De Ruyck et al., 2015). Several in vitro studies have shown that exposure to mycotoxins affects apoptosis, intestinal barrier integrity and mucus production and causes DNA damage, suggesting a possible role of mycotoxins in CRC development; reviewed by Maresca and Fantini (2010).

\section{HOST-MICROBIOME INTERACTION AND DISEASE DEVELOPMENT}

Host derived proteoglycans, forming the mucus layer, are an important part of the mucosal immune system. They protect the epithelium from an extensive contact with the microbiome and reduce the risk of microbial invasion. The oral cavity and esophagus harbor several layers of tight and largely inert squamous epithelium, whereas the remaining parts of the digestive tract are covered with a single layer of intensely active cells (Johansson et al., 2013). The structure of the mucus layers and types of mucin (MUC) vary widely along the digestive tract. The salivary glands in the oral cavity produce mainly MUC5B and MUC7, glands in the stomach and duodenum secrete gel-forming mucins MUC5AC and MUC6, and goblet cells in the gut specialize in MUC2 production (Khan et al., 1998; Wickstrom et al., 1998; Nordman et al., 2002). While in the small intestine, MUC2 forms a loose unattached mucus layer, in the colon it has two parts with different functions, an inner, attached layer and an outer, unattached one (Johansson et al., 2013). The inner layer, which is about 50-100 $\mu \mathrm{m}$ thick, is dense and impenetrable to most microbes, while the outer layer flows with the gut content. Mucus contains distinct products of epithelial cells, such as antimicrobial peptides and secretory IgA, which play an important role in the protection of gut mucosa against pathogen invasion or excessive inflammatory response to commensals (Johansson et al., 2011).

Interestingly, some members of the oral and gut microbiome can form a multilayer structure, composed of microbes and a polymeric matrix, termed a biofilm. Biofilm formation is one example of the mechanisms microorganisms use to evade antimicrobial defenses in the hostile environment of the host. Most biofilms are of polymicrobial nature and members of the biofilm community are distinct from the planktonic microbiota colonizing the mucosal surfaces throughout the body. Polymeric matrix formation and subsequent microbial colonization is the consequence of adhesion processes mediated by a wide spectrum of glycoproteins. Caries and periodontal disease are associated with biofilm formation by well-known periodontopathic bacteria. Biofilm in dental caries contains mainly streptococci, L. acidophilus, and Actinomyces and is secondarily colonized by anaerobic species, such as F. nucleatum and P. gingivalis (Chenicheri et al., 2017). In periodontal disease, early biofilm colonizers are mainly represented by streptococci and Actinomyces. Later on, more pathogenic bacteria such as F. nucleatum, $P$. gingivalis, T. forsythia, T. denticola, and $A$. actinomycetemcomitans appear (Socransky and Haffajee, 2005; Teles et al., 2013). The tendency of some microscopic fungi to form biofilms is also well-established in the literature. Recently, cooperation between Candida and oral commensal streptococci has been described as a significant factor in biofilm formation. Such cohabitation supports Candida growth and survival by providing it with an adhesive surface and the ability to invade tissue by promoting hyphae formation (Diaz et al., 2012).

Current research has confirmed the presence of polymicrobial biofilms on gut mucosa of CRC patients, suggesting their possible role in CRC pathogenesis. Even in healthy mucosa, biofilm formation is associated with oncogenic potential and might be used to predict susceptibility to cancer development (Dejea et al., 2014). These biofilms consist of periodontopathic bacteria F. nucleatum and P. gingivalis, as well as oral commensals, such as Peptostreptococcus, Prevotella, and Parvimonas, and their metabolic products, which may contribute to CRC progression (Li et al., 2017). Microbial biofilms disrupt mucus layers, enabling potentially harmful microbes to attach to or even invade the mucosa and directly affect the epithelial cells by cytotoxic or genotoxic metabolites. Indeed, a recent study by Johnson et al. (2015) has provided evidence that the presence of biofilm increases polyamine metabolites in cancer tissues. Interestingly, fungal genera Phoma and Candida have been detected in higher quantities in adenoma biopsies (Luan et al., 2015). However, to date, the connection of these mixed-species biofilms with CRC has not been thoroughly studied.

When passing from the upper to the lower digestive tract, some previously mentioned bacteria change their oxygen requirements from facultative anaerobic to strict anaerobic, thereby switching to asaccharolytic and proteolytic metabolism (Eley and Cox, 2003). Microbial proteolytic enzymes break down the host's extracellular matrix and soluble factors to get nutrients and invade the tissue. Periodontopathic bacteria produce a wide spectrum of enzymes, including collagenases, elastases, peptidases, etc. For instance, gingipains are cysteine proteases secreted by $P$. gingivalis, classified as either arginine (Rgp) or lysine (Kgp) specific (Potempa et al., 2003). They play a key role in biofilm formation, consequent host tissue destruction and vascular permeability induction (Kadowaki et al., 2000; Eley and Cox, 2003). Some of the $P$. gingivalis proteases can degrade immunologically active molecules, such as immunoglobulins, cytokines and components of the complement, and thus modulate the antibacterial immune response. Similarly, oral streptococci produce proteases which have been shown to cleave IgA1 (Kilian et al., 1988). Interestingly, $88 \%$ of the streptococci that initiate plaque formation on dental enamel possess IgA1 protease activity. Moreover, oral streptococci attack human 


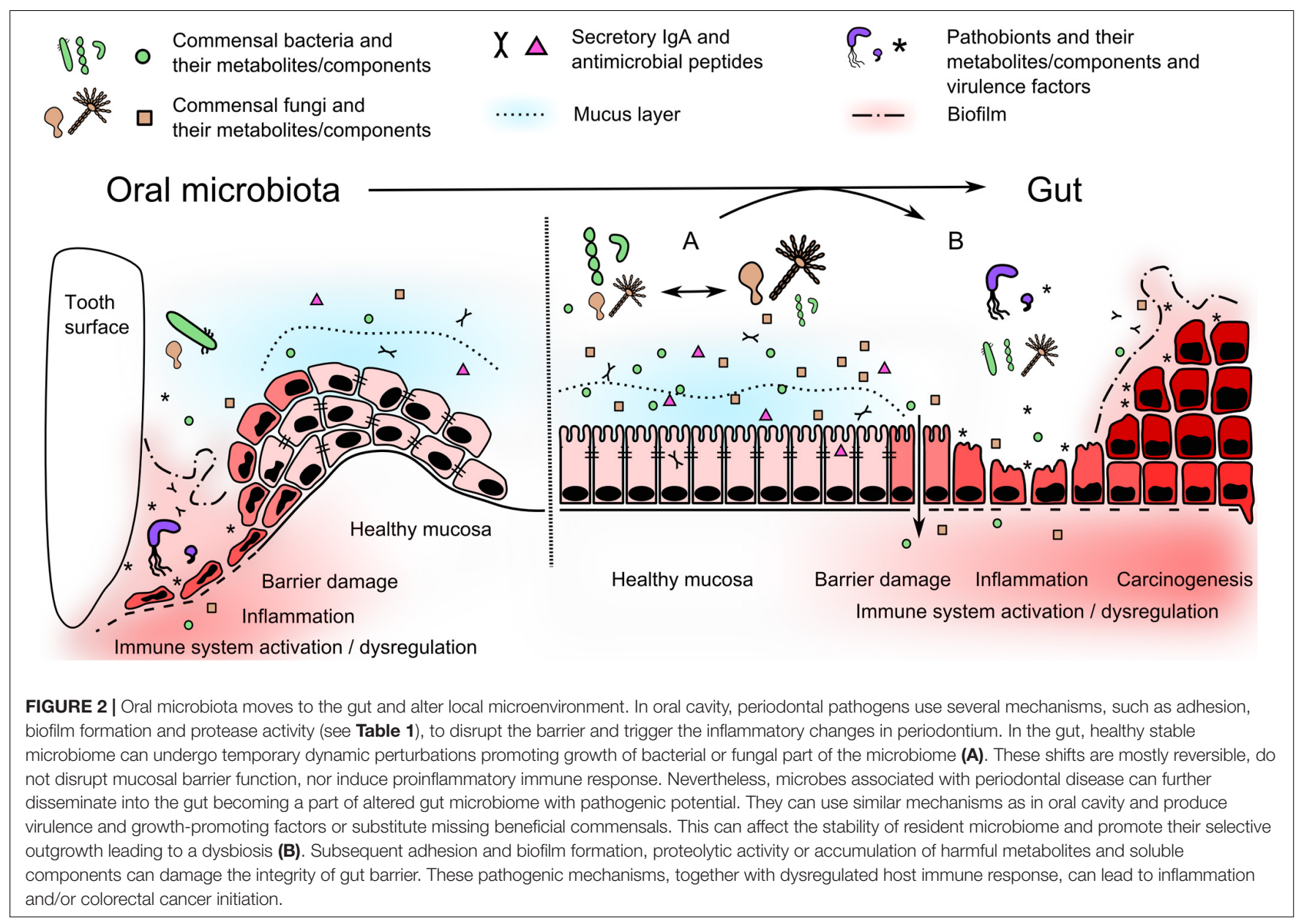

immunoglobulin IgA1 not only by protease production but also by glycosidases (neuraminidase and beta-galactosidase). Oral streptococci thus cleave the alpha chains and also the carbohydrate moiety of IgA1. This finding suggests that the ability of streptococci to evade secretory immune mechanisms is one of the factors that enable them to colonize the oral cavity (Kilian et al., 1989).

Another important feature of the microbiota that protects the host against pathogens is resistance to outsider invasion. Microbiota presents a competitive barrier to pathogenic microbes by active struggle for existence, fighting for nutrients and niche occupation. Moreover, commensals express antimicrobial effector molecules (bacteriocins) that serve as an effective tool for community shaping by endogenous microbiota. The third mechanism is indirect through constitutive stimulation of the mucosal immune system by commensal microbes, which strengthens the mucosal barrier, thus reducing pathogen translocation (Robinson et al., 2010; Stecher and Hardt, 2011; Backhed et al., 2012).

Mucosal surface of the gut is in continuous contact with foreign compounds derived from diet as well as from commensal or pathogenic microorganisms. Therefore, maintaining balance between the inner and outer milieu is the hallmark of the whole mucosal immune system. Many different cell types and their products are involved in this complex dialog, including epithelial and immune cells, cells of supporting tissues, antimicrobial peptides, growth factors, cytokines, and other mediators. Various components of microbiota can differentially trigger cellular pathways that shape local as well as systemic immune response and physiological functions. Recognition of these microbe-associated molecular patterns (MAMPs) is one of the most important features of the mucosal immune system. Receptors facilitating this are known as patternrecognition receptors and can be divided into several families, such as retinoic acid inducible gene I-like receptors, nodlike receptors, toll-like receptors (TLR), and lectin receptors. Proinflammatory processes that are mediated by MAMPs, such as lipopolysaccharide, polysaccharides, peptidoglycan, flagella, and microbial DNA/RNA, activate pattern-recognition receptors on various host cells. These cells elicit local pro-inflammatory response and/or drive the differentiation of adaptive immune response (Sartor, 2008; Underhill and Iliev, 2014). Therefore, a persistent inflammatory reaction of the host, constantly challenging the mucosal immune system, can lead to disease initiation (Tlaskalova-Hogenova et al., 2004). Appropriate immune response requires that recognition of commensals on the apical side of the epithelium induces tolerance, while recognition of pathogens on the basolateral membrane or inside 
the cell induces inflammation. Moreover, TLRs are important for stimulation of gut epithelium growth and barrier integrity as well as production of mucus, secretory IgA, antimicrobial peptides, and chemokines (Abreu, 2010). Generally, the expression of TLRs in the epithelium is low in the steady state but increases during inflammation. Indeed, recent studies suggested the association of $T L R$ polymorphisms with the progression of IBD into CRC, as TLRs expression is changed during gut inflammation (Bank et al., 2015).

Chronic inflammation leads to massive accumulation of activated immune cells and their mediators (cytokines and chemokines), residues of damaged cells, and large amounts of oxygen and nitrogen reactive species. Isolated dysplastic cells are further modified by the local microenvironment, as proinflammatory cells and cytokines promote the progression of dysplasia into carcinoma. During chronic inflammation, innate immune cells produce excessive quantities of reactive oxygen and nitrogen species that cause DNA and cellular damage. Pattern-recognition receptors signalization in the milieu of chronic inflammation activates MyD88-dependent pathways that promote pro-inflammatory cytokine release and subsequent tumor progression (Tlaskalova-Hogenova et al., 2014).

\section{CONCLUSION}

There are two fundamental links between microbes and diseases. The first involves the host's recognition and immune response mechanisms and the second involves the microbiota itself, its presence and metabolic activity. Impaired barrier function, inadequate activation of the innate immune system and dysregulation of the appropriate mucosal immune response to gut microbiota (tolerance) are the primary elements of disease development. Low microbiome diversity seems to be a common feature in the pathogenesis of diseases of the

\section{REFERENCES}

Aagaard, K., Ma, J., Antony, K. M., Ganu, R., Petrosino, J., and Versalovic, J. (2014). The placenta harbors a unique microbiome. Sci. Transl. Med. 6:237ra65. doi: 10.1126/scitranslmed.3008599

Aas, J. A., Paster, B. J., Stokes, L. N., Olsen, I., and Dewhirst, F. E. (2005). Defining the normal bacterial flora of the oral cavity. J. Clin. Microbiol. 43, 5721-5732. doi: 10.1128/Jcm.43.11.5721-5732.2005

Abed, J., Emgard, J. E. M., Zamir, G., Faroja, M., Almogy, G., Grenov, A., et al. (2016). Fap2 mediates Fusobacterium nucleatum colorectal adenocarcinoma enrichment by binding to tumor-expressed Gal-GalNAc. Cell Host Microbe 20, 215-225. doi: 10.1016/j.chom.2016.07.006

Abreu, M. T. (2010). Toll-like receptor signalling in the intestinal epithelium: how bacterial recognition shapes intestinal function. Nat. Rev. Immunol. 10, 131-144. doi: 10.1038/nri2707

Adlerberth, I., and Wold, A. E. (2009). Establishment of the gut microbiota in Western infants. Acta Paediatr. 98, 229-238. doi: 10.1111/j.1651-2227.2008. 01060.x

Amitay, E. L., Werner, S., Vital, M., Pieper, D. H., Hofler, D., Gierse, I. J., et al. (2017). Fusobacterium and colorectal cancer: causal factor or passenger? Results from a large colorectal cancer screening study. Carcinogenesis 38, 781-788. doi: $10.1093 /$ carcin/bgx053

Arthur, J. C., and Jobin, C. (2011). The struggle within: microbial influences on colorectal cancer. Inflamm. Bowel Dis. 17, 396-409. doi: 10.1002/ibd.21354 digestive tract, suggesting that high microbial richness, both bacterial and fungal, is crucial for physiological homeostasis. Normally, a dynamic balance is maintained, where reduction of the bacterial community leads to outgrowth of the fungal one and vice versa. Disruption of this balance is associated with outgrowth of certain pathobionts at the expense of a complex community and may lead to disease initiation (Figure 2). Established dysbiosis is supported by local proinflammatory and tumor microenvironment which creates distinct nutritional conditions. A growing body of literature dealing with microbiome metabolic activities gradually unravels the complex host-microbe interactions. Nevertheless, collecting data about these interactions at the time of disease development is especially challenging in humans. In this respect, we still have to rely on retrospective clinical studies and animal models to generate helpful insights. Elucidation of the underlying mechanisms involving the interactions of the immune system with the microbiome, pathogens, or pathobionts can lead to the development of early screening and preventive interventions and, ultimately, reduce the risk of severe colon cancer.

\section{AUTHOR CONTRIBUTIONS}

KK, ZJZ, and HT-H wrote the manuscript and approved its final version.

\section{FUNDING}

The authors are supported by Czech Science Foundation (1706632Y and 16-06326S), Ministry of Health of the Czech Republic (15-27580A, 15-29336A, 15-28064A, and 15-30782A), and Institutional Research Concept (RVO: 61388971).

Arthur, J. C., Perez-Chanona, E., Muhlbauer, M., Tomkovich, S., Uronis, J. M., Fan, T. J., et al. (2012). Intestinal inflammation targets cancer-inducing activity of the microbiota. Science 338, 120-123. doi: 10.1126/science. 1224820

Arumugam, M., Raes, J., Pelletier, E., Le Paslier, D., Yamada, T., Mende, D. R., et al. (2011). Enterotypes of the human gut microbiome. Nature 473, 174-180. doi: 10.1038/nature09944

Backhed, F., Fraser, C. M., Ringel, Y., Sanders, M. E., Sartor, R. B., Sherman, P. M., et al. (2012). Defining a healthy human gut microbiome: current concepts, future directions, and clinical applications. Cell Host Microbe 12, 611-622. doi: 10.1016/j.chom.2012.10.012

Bank, S., Andersen, P. S., Burisch, J., Pedersen, N., Roug, S., Galsgaard, J., et al. (2015). Polymorphisms in the toll-like receptor and the IL-23/IL-17 pathways were associated with susceptibility to inflammatory bowel disease in a danish cohort. PLoS One 10:e0145302. doi: 10.1371/journal.pone.0145302

Bankvall, M., Sjoberg, F., Gale, G., Wold, A., Jontell, M., and Ostman, S. (2014). The oral microbiota of patients with recurrent aphthous stomatitis. J. Oral Microbiol. 6:25739. doi: 10.3402/Jom.V6.25739

Bartova, J., Sommerova, P., Lyuya-Mi, Y., Mysak, J., Prochazkova, J., Duskova, J., et al. (2014). Periodontitis as a risk factor of atherosclerosis. J. Immunol. Res. 2014:636893. doi: 10.1155/2014/636893

Blazkova, H., Krejcikova, K., Moudry, P., Frisan, T., Hodny, Z., and Bartek, J. (2010). Bacterial intoxication evokes cellular senescence with persistent DNA damage and cytokine signalling. J. Cell Mol. Med. 14, 357-367. doi: 10.1111/j. 1582-4934.2009.00862.x 
Boursi, B., Haynes, K., Mamtani, R., and Yang, Y. X. (2015). Impact of antibiotic exposure on the risk of colorectal cancer. Pharmacoepidemiol. Drug Saf. 24, 534-542. doi: 10.1002/pds.3765

Canabarro, A., Valle, C., Farias, M. R., Santos, F. B., Lazera, M., and Wanke, B. (2013). Association of subgingival colonization of Candida albicans and other yeasts with severity of chronic periodontitis. J. Periodontal Res. 48, 428-432. doi: $10.1111 /$ jre.12022

Carlsson, J., Larsen, J. T., and Edlund, M. B. (1993). Peptostreptococcus micros has a uniquely high capacity to form hydrogen sulfide from glutathione. Oral Microbiol. Immunol. 8, 42-45. doi: 10.1111/j.1399-302X.1993.tb00541.x

Casarin, R. C., Saito, D., Santos, V. R., Pimentel, S. P., Duarte, P. M., Casati, M. Z., et al. (2012). Detection of Mogibacterium timidum in subgingival biofilm of aggressive and non-diabetic and diabetic chronic periodontitis patients. Braz. J. Microbiol. 43, 931-937. doi: 10.1590/S1517-838220120003000012

Castellarin, M., Warren, R. L., Freeman, J. D., Dreolini, L., Krzywinski, M., Strauss, J., et al. (2012). Fusobacterium nucleatum infection is prevalent in human colorectal carcinoma. Genome Res. 22, 299-306. doi: 10.1101/gr.1265 16.111

Chehoud, C., Albenberg, L. G., Judge, C., Hoffmann, C., Grunberg, S., Bittinger, K., et al. (2015). Fungal signature in the gut microbiota of pediatric patients with inflammatory bowel disease. Inflamm. Bowel Dis. 21, 1948-1956. doi: 10.1097/ MIB.0000000000000454

Chenicheri, S., Usha, R., Ramachandran, R., Thomas, V., and Wood, A. (2017). Insight into oral biofilm: primary, secondary and residual caries and phyto-challenged solutions. Open Dent J. 11, 312-333. doi: 10.2174/ 1874210601711010312

Claesson, R., Edlund, M. B., Persson, S., and Carlsson, J. (1990). Production of volatile sulfur compounds by various Fusobacterium species. Oral Microbiol. Immunol. 5, 137-142. doi: 10.1111/j.1399-302X.1990.tb00411.x

Cobb, C. M., Kelly, P. J., Williams, K. B., Babbar, S., Angolkar, M., and Derman, R. J. (2017). The oral microbiome and adverse pregnancy outcomes. Int. J. Womens Health 9, 551-559. doi: 10.2147/Ijwh.S142730

Costalonga, M., and Herzberg, M. C. (2014). The oral microbiome and the immunobiology of periodontal disease and caries. Immunol. Lett. 162, 22-38. doi: 10.1016/j.imlet.2014.08.017

da Silva, E. S., Feres, M., Figueiredo, L. C., Shibli, J. A., Ramiro, F. S., and Faveri, M. (2014). Microbiological diversity of peri-implantitis biofilm by Sanger sequencing. Clin. Oral Implants Res. 25, 1192-1199. doi: 10.1111/clr. 12231

Darveau, R. P., Hajishengallis, G., and Curtis, M. A. (2012). Porphyromonas gingivalis as a potential community activist for disease. J. Dent. Res. 91, 816-820. doi: 10.1177/0022034512453589

De Ruyck, K., De Boevre, M., Huybrechts, I., and De Saeger, S. (2015). Dietary mycotoxins, co-exposure, and carcinogenesis in humans: short review. Mutat. Res. Rev. Mutat. Res. 766, 32-41. doi: 10.1016/j.mrrev.2015.07.003

Dejea, C. M., Wick, E. C., Hechenbleikner, E. M., White, J. R., Mark Welch, J. L., Rossetti, B. J., et al. (2014). Microbiota organization is a distinct feature of proximal colorectal cancers. Proc. Natl. Acad. Sci. U.S.A. 111, 18321-18326. doi: 10.1073/pnas.1406199111

Diaz, P. I., Xie, Z. H., Sobue, T., Thompson, A., Biyikoglu, B., Ricker, A., et al. (2012). Synergistic interaction between Candida albicans and commensal oral streptococci in a novel in vitro mucosal model. Infect. Immun. 80, 620-632. doi: 10.1128/Iai.05896-11

Dupuy, A. K., David, M. S., Li, L., Heider, T. N., Peterson, J. D., Montano, E. A., et al. (2014). Redefining the human oral mycobiome with improved practices in amplicon-based taxonomy: discovery of malassezia as a prominent commensal. PLoS One 9:e90899. doi: 10.1371/journal.pone.0090899

Egeberg, A., Mallbris, L., Gislason, G., Hansen, P. R., and Mrowietz, U. (2017). Risk of periodontitis in patients with psoriasis and psoriatic arthritis. J. Eur. Acad. Dermatol. Venereol. 31, 288-293. doi: 10.1111/jdv.13814

El-Aouar, R. A., Nicolas, A., Castro, T. L. D., Deplanche, M., Azevedo, V. A. D., Goossens, P. L., et al. (2017). Heterogeneous family of cyclomodulins: smart weapons that allow bacteria to hijack the eukaryotic cell cycle and promote infections. Front. Cell Infect. Microbiol. 7:208. doi: 10.3389/Fcimb.2017.00364

Eley, B. M., and Cox, S. W. (2003). Proteolytic and hydrolytic enzymes from putative periodontal pathogens: characterization, molecular genetics, effects on host defenses and tissues and detection in gingival crevice fluid. Periodontol 31, 105-124. doi: 10.1034/j.1600-0757.2003.03107.x
Fan, X., Alekseyenko, A. V., Wu, J., Jacobs, E. J., Gapstur, S. M., Purdue, M. P., et al. (2016). Human oral microbiome and prospective risk for pancreatic cancer: a population based, nested case control study. Cancer Res. 76:4350. doi: 10.1158/1538-7445.AM2016-4350

Ferlay, J., Soerjomataram, I., Dikshit, R., Eser, S., Mathers, C., Rebelo, M., et al. (2015). Cancer incidence and mortality worldwide: sources, methods and major patterns in GLOBOCAN 2012. Int. J. Cancer 136, E359-E386. doi: 10.1002/ijc. 29210

Flanagan, L., Schmid, J., Ebert, M., Soucek, P., Kunicka, T., Liska, V., et al. (2014). Fusobacterium nucleatum associates with stages of colorectal neoplasia development, colorectal cancer and disease outcome. Eur. J. Clin. Microbiol. Infect. Dis. 33, 1381-1390. doi: 10.1007/s10096-014-2081-3

Flemer, B., Lynch, D. B., Brown, J. M., Jeffery, I. B., Ryan, F. J., Claesson, M. J., et al. (2017). Tumour-associated and non-tumour-associated microbiota in colorectal cancer. Gut 66, 633-643. doi: 10.1136/gutjnl-2015-309595

Ford, P. J., Gemmell, E., Chan, A., Carter, C. L., Walker, P. J., Bird, P. S., et al. (2006). Inflammation, heat shock proteins and periodontal pathogens in atherosclerosis: an immunohistologic study. Oral Microbiol. Immunol. 21, 206-211. doi: 10.1111/j.1399-302X.2006.00276.x

Ford, P. J., Gemmell, E., Hamlet, S. M., Hasan, A., Walker, P. J., West, M. J., et al. (2005). Cross-reactivity of GroEL antibodies with human heat shock protein 60 and quantification of pathogens in atherosclerosis. Oral Microbiol. Immunol. 20, 296-302. doi: 10.1111/j.1399-302X.2005.00230.x

Gagniere, J., Raisch, J., Veziant, J., Barnich, N., Bonnet, R., Buc, E., et al. (2016). Gut microbiota imbalance and colorectal cancer. World J. Gastroenterol. 22, 501-518. doi: 10.3748/wjg.v22.i2.501

Ghannoum, M. A., Jurevic, R. J., Mukherjee, P. K., Cui, F., Sikaroodi, M., Naqvi, A., et al. (2010). Characterization of the oral fungal microbiome (Mycobiome) in healthy individuals. PLoS Pathog. 6:e1000713. doi: 10.1371/journal.ppat. 1000713

Gill, S. R., Pop, M., DeBoy, R. T., Eckburg, P. B., Turnbaugh, P. J., Samuel, B. S., et al. (2006). Metagenomic analysis of the human distal gut microbiome. Science 312, 1355-1359. doi: 10.1126/science.1124234

Gomes, C. C., Guimarães, L. S., Pinto, L. C. C., Camargo, G. A. D. C. G., Valente, M. I. B., and Sarquis, M. I. M. (2017). Investigations of the prevalence and virulence of Candida albicans in periodontal and endodontic lesions in diabetic and normoglycemic patients. J. Appl. Oral Sci. 25, 274-281. doi: 10.1590/16787757-2016-0432

Greenwald, R. A., and Kirkwood, K. (1999). Adult periodontitis as a model for rheumatoid arthritis (with emphasis on treatment strategies). J. Rheumatol. 26, 1650-1653.

Hajishengallis, G., and Korostoff, J. M. (2017). Revisiting the page \& schroeder model: the good, the bad and the unknowns in the periodontal host response 40 years later. Periodontol 75, 116-151. doi: 10.1111/prd.12181

Hale, V. L., Chen, J., Johnson, S., Harrington, S. C., Yab, T. C., Smyrk, T. C., et al. (2017). Shifts in the fecal microbiota associated with adenomatous polyps. Cancer Epidemiol. Biomarkers Prev. 26, 85-94. doi: 10.1158/1055-9965.EPI-160337

Han, Y. W. (2015). Fusobacterium nucleatum: a commensal-turned pathogen. Curr. Opin. Microbiol. 23, 141-147. doi: 10.1016/j.mib.2014.11.013

He, J. Z., Li, Y., Cao, Y. P., Xue, J., and Zhou, X. D. (2015). The oral microbiome diversity and its relation to human diseases. Folia Microbiol. 60, 69-80. doi: 10.1007/s12223-014-0342-2

Heijl, L., Wennstrom, J., Lindhe, J., and Socransky, S. S. (1980). Periodontal-disease in gnotobiotic-rats. J. Periodontal Res. 15, 405-419. doi: 10.1111/j.1600-0765. 1980.tb00298.x

Hoffmann, C., Dollive, S., Grunberg, S., Chen, J., Li, H., Wu, G. D., et al. (2013). Archaea and fungi of the human gut microbiome: correlations with diet and bacterial residents. PLoS One 8:e66019. doi: 10.1371/journal.pone.00 66019

Huffnagle, G. B., and Noverr, M. C. (2013). The emerging world of the fungal microbiome. Trends Microbiol. 21, 334-341. doi: 10.1016/j.tim.2013.04.002

Human Microbiome Project Consortium (2012). Structure, function and diversity of the healthy human microbiome. Nature 486, 207-214. doi: 10.1038/ nature11234

Huse, S. M., Ye, Y. Z., Zhou, Y. J., and Fodor, A. A. (2012). A core human microbiome as viewed through $16 \mathrm{~S}$ rRNA sequence clusters. PLoS One 7:e34242. doi: 10.1371/journal.pone.0034242 
Huycke, M. M., Abrams, V., and Moore, D. R. (2002). Enterococcus faecalis produces extracellular superoxide and hydrogen peroxide that damages colonic epithelial cell DNA. Carcinogenesis 23, 529-536. doi: 10.1093/carcin/23.3.529

Inaba, H., Sugita, H., Kuboniwa, M., Iwai, S., Hamada, M., Noda, T., et al. (2013). Porphyromonas gingivalis promotes invasion of oral squamous cell carcinoma through induction of proMMP9 and its activation. Cell Microbiol. 16, 131-145. doi: $10.1111 / \mathrm{cmi} .12211$

Ivanyi, L., Newman, H. N., and Marsh, P. D. (1991). T-cell proliferative responses to molecular fractions of periodontopathic bacteria. Clin. Exp. Immunol. 83, 108-111. doi: 10.1111/j.1365-2249.1991.tb05597.x

Johansson, M. E., Larsson, J. M., and Hansson, G. C. (2011). The two mucus layers of colon are organized by the MUC2 mucin, whereas the outer layer is a legislator of host-microbial interactions. Proc. Natl. Acad. Sci. U.S.A. 108, 4659-4665. doi: 10.1073/pnas.1006451107

Johansson, M. E., Sjovall, H., and Hansson, G. C. (2013). The gastrointestinal mucus system in health and disease. Nat. Rev. Gastroenterol. Hepatol. 10, 352-361. doi: 10.1038/nrgastro.2013.35

Johnson, C. H., Dejea, C. M., Edler, D., Hoang, L. T., Santidrian, A. F., Felding, B. H., et al. (2015). Metabolism links bacterial biofilms and colon carcinogenesis. Cell Metab. 21, 891-897. doi: 10.1016/j.cmet.2015.04.011

Kadowaki, T., Nakayama, K., Okamoto, K., Abe, N., Baba, A., Shi, Y. X., et al. (2000). Porphyromonas gingivalis proteinases as virulence determinants in progression of periodontal diseases. J. Biochem. 128, 153-159. doi: 10.1093/ oxfordjournals.jbchem.a022735

Kaiko, G. E., Ryu, S. H., Koues, O. I., Collins, P. L., Solnica-Krezel, L., Pearce, E. J., et al. (2016). The colonic crypt protects stem cells from microbiota-derived metabolites. Cell 165, 1708-1720. doi: 10.1016/j.cell.2016.10.034

Kasser, U. R., Gleissner, C., Dehne, F., Michel, A., Willershausen-Zonnchen, B., and Bolten, W. W. (1997). Risk for periodontal disease in patients with longstanding rheumatoid arthritis. Arthritis Rheum. 40, 2248-2251. doi: 10. 1002/art.1780401221

Khan, S. H., Aguirre, A., and Bobek, L. A. (1998). In-situ hybridization localized MUC7 mucin gene expression to the mucous acinar cells of human and MUC7transgenic mouse salivary glands. Glycoconj. J. 15, 1125-1132. doi: 10.1023/A: 1006955604501

Kilian, M., Mestecky, J., and Russell, M. W. (1988). Defense mechanisms involving Fc-dependent functions of immunoglobulin A and their subversion by bacterial immunoglobulin A proteases. Microbiol. Rev. 52, 296-303.

Kilian, M., Reinholdt, J., Nyvad, B., Frandsen, E. V., and Mikkelsen, L. (1989). IgA1 proteases of oral streptococci: ecological aspects. Immunol. Invest. 18, 161-170. doi: 10.3109/08820138909112235

Kim, Y. J., Choi, Y. S., Baek, K. J., Yoon, S. H., Park, H. K., and Choi, Y. (2016). Mucosal and salivary microbiota associated with recurrent aphthous stomatitis. BMC Microbiol. 16:57. doi: 10.1186/s12866-016-0673-z

Kinane, D. F., Stathopoulou, P. G., and Papapanou, P. N. (2017). Periodontal diseases. Nat. Rev. Dis. Primers 3:17038. doi: 10.1038/Nrdp.2017.38

Klimesova, K., Kverka, M., Zakostelska, Z., Hudcovic, T., Hrncir, T., Stepankova, R., et al. (2013). Altered gut microbiota promotes colitis-associated cancer in IL-1 receptor-associated kinase M-deficient mice. Inflamm. Bowel Dis. 19, 1266-1277. doi: 10.1097/MIB.0b013e318281330a

Kostic, A. D., Chun, E. Y., Robertson, L., Glickman, J. N., Gallini, C. A., Michaud, M., et al. (2013). Fusobacterium nucleatum potentiates intestinal tumorigenesis and modulates the tumor-immune microenvironment. Cell Host Microbe 14, 207-215. doi: 10.1016/j.chom.2013.07.007

Kostic, A. D., Gevers, D., Pedamallu, C. S., Michaud, M., Duke, F., Earl, A. M., et al. (2012). Genomic analysis identifies association of Fusobacterium with colorectal carcinoma. Genome Res. 22, 292-298. doi: 10.1101/gr.126 573.111

Li, S., Konstantinov, S. R., Smits, R., and Peppelenbosch, M. P. (2017). Bacterial biofilms in colorectal cancer initiation and progression. Trends Mol. Med. 23, 18-30. doi: 10.1016/j.molmed.2016.11.004

Liang, Q., Chiu, J., Chen, Y., Huang, Y., Higashimori, A., Fang, J., et al. (2017). Fecal bacteria act as novel biomarkers for noninvasive diagnosis of colorectal cancer. Clin. Cancer Res. 23, 2061-2070. doi: 10.1158/1078-0432.CCR-161599

Liguori, G., Lamas, B., Richard, M. L., Brandi, G., da Costa, G., Hoffmann, T. W., et al. (2016). Fungal dysbiosis in mucosa-associated microbiota of crohn's disease patients. J. Crohns Colitis 10, 296-305. doi: 10.1093/ecco-jcc/jjv209
Louis, P., Young, P., Holtrop, G., and Flint, H. J. (2010). Diversity of human colonic butyrate-producing bacteria revealed by analysis of the butyryl-CoA: acetate CoA-transferase gene. Environ. Microbiol. 12, 304-314. doi: 10.1111/j.14622920.2009.02066.x

Lu, Y., Chen, J., Zheng, J., Hu, G., Wang, J., Huang, C., et al. (2016). Mucosal adherent bacterial dysbiosis in patients with colorectal adenomas. Sci. Rep. 6:26337. doi: 10.1038/srep26337

Luan, C., Xie, L., Yang, X., Miao, H., Lv, N., Zhang, R., et al. (2015). Dysbiosis of fungal microbiota in the intestinal mucosa of patients with colorectal adenomas. Sci. Rep. 5:7980. doi: 10.1038/srep07980

Macfarlane, G. T., and Macfarlane, S. (2012). Bacteria, colonic fermentation, and gastrointestinal health. J. AOAC Int. 95, 50-60. doi: 10.5740/jaoacint.SGE_ Macfarlane

Maffei, V. J., Kim, S., Blanchard, E., Luo, M., Jazwinski, S. M., Taylor, C. M., et al. (2017). Biological aging and the human gut microbiota. J. Gerontol. A Biol. Sci. Med. Sci. 72, 1474-1482. doi: 10.1093/gerona/glx042

Mager, D. L., Ximenez-Fyvie, L. A., Haffajee, A. D., and Socransky, S. S. (2003). Distribution of selected bacterial species on intraoral surfaces. J. Clin. Periodontol. 30, 644-654. doi: 10.1034/j.1600-051X.2003.00376.x

Mao, S., Park, Y., Hasegawa, Y., Tribble, G. D., James, C. E., Handfield, M., et al. (2007). Intrinsic apoptotic pathways of gingival epithelial cells modulated by Porphyromonas gingivalis. Cell Microbiol. 9, 1997-2007. doi: 10.1111/j.14625822.2007.00931.X

Marchesan, J., Jiao, Y., Schaff, R. A., Hao, J., Morelli, T., Kinney, J. S., et al. (2016). TLR4, NOD1 and NOD2 mediate immune recognition of putative newly identified periodontal pathogens. Mol. Oral Microbiol. 31, 243-258. doi: $10.1111 /$ omi.12116

Marcotte, H., and Lavoie, M. C. (1998). Oral microbial ecology and the role of salivary immunoglobulin A. Microbiol. Mol. Biol. Rev. 62, 71-109.

Maresca, M., and Fantini, J. (2010). Some food-associated mycotoxins as potential risk factors in humans predisposed to chronic intestinal inflammatory diseases. Toxicon 56, 282-294. doi: 10.1016/j.toxicon.2010.04.016

Mehta, R. S., Nishihara, R., Cao, Y., Song, M., Mima, K., Qian, Z. R., et al. (2017). Association of dietary patterns with risk of colorectal cancer subtypes classified by Fusobacterium nucleatum in tumor tissue. JAMA Oncol. 3, 921-927. doi: 10.1001/jamaoncol.2016.6374

Miraglia, A. G., Travaglione, S., Meschini, S., Falzano, L., Matarrese, P., Quaranta, M. G., et al. (2007). Cytotoxic necrotizing factor 1 prevents apoptosis via the Akt/IkappaB kinase pathway: role of nuclear factor-kappaB and Bcl-2. Mol. Biol. Cell 18, 2735-2744. doi: 10.1091/mbc.E06-10-0910

Momen-Heravi, F., Babic, A., Tworoger, S. S., Zhang, L., Wu, K., Smith-Warner, S. A., et al. (2017). Periodontal disease, tooth loss and colorectal cancer risk: results from the Nurses' Health Study. Int. J. Cancer 140, 646-652. doi: 10.1002/ ijc.30486

Mukherjee, P. K., Chandra, J., Retuerto, M., Sikaroodi, M., Brown, R. E., Jurevic, R., et al. (2014). Oral mycobiome analysis of HIV-infected patients: identification of Pichia as an antagonist of opportunistic fungi. PLoS Pathog. 10:e1003996. doi: 10.1371/journal.ppat.1003996

Nagano, Y., Elborn, J. S., Miller, B. C., Walker, J. M., Goldsmith, C. E., Rendall, J., et al. (2010). Comparison of techniques to examine the diversity of fungi in adult patients with cystic fibrosis. Med. Mycol. 48, 166-176. doi: 10.3109/ 13693780903127506

Nakatsu, G., Li, X. C., Zhou, H. K., Sheng, J. Q., Wong, S. H., Wu, W. K. K., et al. (2015). Gut mucosal microbiome across stages of colorectal carcinogenesis. Nat. Commun. 6:8727. doi: 10.1038/Ncomms9727

Nordman, H., Davies, J. R., Lindell, G., de Bolos, C., Real, F., and Carlstedt, I. (2002). Gastric MUC5AC and MUC6 are large oligomeric mucins that differ in size, glycosylation and tissue distribution. Biochem. J. 364, 191-200. doi: 10.1042/bj3640191

Nougayrede, J. P., Homburg, S., Taieb, F., Boury, M., Brzuszkiewicz, E., Gottschalk, G., et al. (2006). Escherichia coli induces DNA double-strand breaks in eukaryotic cells. Science 313, 848-851. doi: 10.1126/science.1127059

Papadopoulos, G., Weinberg, E. O., Massari, P., Gibson, F. C. III, Wetzler, L. M., Morgan, E. F., et al. (2013). Macrophage-specific TLR2 signaling mediates pathogen-induced TNF-dependent inflammatory oral bone loss. J. Immunol. 190, 1148-1157. doi: 10.4049/jimmunol.1202511

Park, H. E., Kim, J. H., Cho, N. Y., Lee, H. S., and Kang, G. H. (2017). Intratumoral Fusobacterium nucleatum abundance correlates with macrophage infiltration 
and CDKN2A methylation in microsatellite-unstable colorectal carcinoma. Virchows Arch. 471, 329-336. doi: 10.1007/s00428-017-2171-6

Persson, S., Edlund, M. B., Claesson, R., and Carlsson, J. (1990). The formation of hydrogen sulfide and methyl mercaptan by oral bacteria. Oral Microbiol. Immunol. 5, 195-201. doi: 10.1111/j.1399-302X.1990.tb00645.x

Peters, B. A., Dominianni, C., Shapiro, J. A., Church, T. R., Wu, J., Miller, G., et al. (2016). The gut microbiota in conventional and serrated precursors of colorectal cancer. Microbiome 4:69. doi: 10.1186/s40168-016-0218-6

Peters, B. A., Wu, J., Hayes, R. B., and Ahn, J. (2017). The oral fungal mycobiome: characteristics and relation to periodontitis in a pilot study. BMC Microbiol. 17:157. doi: 10.1186/s12866-017-1064-9

Pitts, N. B., Zero, D. T., Marsh, P. D., Ekstrand, K., Weintraub, J. A., RamosGomez, F., et al. (2017). Dental caries. Nat. Rev. Dis. Primers 3:17030. doi: $10.1038 /$ nrdp. 2017.30

Potempa, J., Sroka, A., Imamura, T., and Travis, J. (2003). Gingipains, the major cysteine proteinases and virulence factors of Porphyromonas gingivalis: structure, function and assembly of multidomain protein complexes. Curr. Protein Pept. Sci. 4, 397-407. doi: 10.2174/1389203033487036

Potgieter, M., Bester, J., Kell, D. B., and Pretorius, E. (2015). The dormant blood microbiome in chronic, inflammatory diseases. FEMS Microbiol. Rev. 39, 567-591. doi: 10.1093/femsre/fuv013

Proctor, D. M., and Relman, D. A. (2017). The landscape ecology and microbiota of the human nose, mouth, and throat. Cell Host Microbe 21, 421-432. doi: 10.1016/j.chom.2017.03.011

Qin, J., Li, R., Raes, J., Arumugam, M., Burgdorf, K. S., Manichanh, C., et al. (2010). A human gut microbial gene catalogue established by metagenomic sequencing. Nature 464, 59-65. doi: 10.1038/nature08821

Raisch, J., Buc, E., Bonnet, M., Sauvanet, P., Vazeille, E., de Vallee, A., et al. (2014). Colon cancer-associated B2 Escherichia coli colonize gut mucosa and promote cell proliferation. World J. Gastroenterol. 20, 6560-6572. doi: 10.3748/wjg.v20. i2 1.6560

Reddy, B. S., Narisawa, T., Maronpot, R., Weisburger, J. H., and Wynder, E. L. (1975). Animal models for the study of dietary factors and cancer of the large bowel. Cancer Res. 35, 3421-3426.

Roberts, F. A., and Darveau, R. P. (2015). Microbial protection and virulence in periodontal tissue as a function of polymicrobial communities: symbiosis and dysbiosis. Periodontol 69, 18-27. doi: 10.1111/prd.12087

Robinson, C. J., Bohannan, B. J. M., and Young, V. B. (2010). From structure to function: the ecology of host-associated microbial communities. Microbiol. Mol. Biol. R 74, 453-476. doi: 10.1128/Mmbr.00014-10

Rubinstein, M. R., Wang, X., Liu, W., Hao, Y., Cai, G., and Han, Y. W. (2013). Fusobacterium nucleatum promotes colorectal carcinogenesis by modulating E-cadherin/beta-catenin signaling via its FadA adhesin. Cell Host Microbe 14, 195-206. doi: 10.1016/j.chom.2013.07.012

Sartor, R. B. (2008). Microbial influences in inflammatory bowel diseases. Gastroenterology 134, 577-594. doi: 10.1053/j.gastro.2007.11.059

Saunders, C. W., Scheynius, A., and Heitman, J. (2012). Malassezia fungi are specialized to live on skin and associated with dandruff, eczema, and other skin diseases. PLoS Pathog. 8:e1002701. doi: 10.1371/journal.ppat. 1002701

Segata, N., Haake, S. K., Mannon, P., Lemon, K. P., Waldron, L., Gevers, D., et al. (2012). Composition of the adult digestive tract bacterial microbiome based on seven mouth surfaces, tonsils, throat and stool samples. Genome Biol. 13:R42. doi: 10.1186/gb-2012-13-6-r42

Shen, X. J., Rawls, J. F., Randall, T., Burcal, L., Mpande, C. N., Jenkins, N., et al. (2010). Molecular characterization of mucosal adherent bacteria and associations with colorectal adenomas. Gut Microbes 1, 138-147. doi: 10.4161/ gmic.1.3.12360

Slots, J. (1976). Predominant cultivable organisms in juvenile periodontitis. Scand. J. Dent. Res. 84, 1-10. doi: 10.1111/j.1600-0722.1976.tb00454.x

Socransky, S. S., and Haffajee, A. D. (2002). Dental biofilms: difficult therapeutic targets. Periodontol 28, 12-55. doi: 10.1034/j.1600-0757.2002.28 0102.x

Socransky, S. S., and Haffajee, A. D. (2005). Periodontal microbial ecology. Periodontol 38, 135-187. doi: 10.1111/j.1600-0757.2005.00107.x

Socransky, S. S., Haffajee, A. D., Cugini, M. A., Smith, C., and Kent, R. L. (1998). Microbial complexes in subgingival plaque. J. Clin. Periodontol. 25, 134-144. doi: 10.1111/j.1600-051X.1998.tb02419.x
Sokol, H., Leducq, V., Aschard, H., Pham, H. P., Jegou, S., Landman, C., et al. (2017). Fungal microbiota dysbiosis in IBD. Gut 66, 1039-1048. doi: 10.1136/ gutjnl-2015-310746

Sousa, E. L., Martinho, F. C., Leite, F. R., Nascimento, G. G., and Gomes, B. P. (2014). Macrophage cell activation with acute apical abscess contents determined by interleukin-1 Beta and tumor necrosis factor alpha production. J. Endod. 40, 1752-1757. doi: 10.1016/j.joen.2014.06.019

Stecher, B., and Hardt, W. D. (2011). Mechanisms controlling pathogen colonization of the gut. Curr. Opin. Microbiol. 14, 82-91. doi: 10.1016/j.mib. 2010.10.003

Swidsinski, A., Khilkin, M., Kerjaschki, D., Schreiber, S., Ortner, M., Weber, J., et al. (1998). Association between intraepithelial Escherichia coli and colorectal cancer. Gastroenterology 115, 281-286. doi: 10.1016/S0016-5085(98)70194-5

Taieb, F., Nougayrede, J. P., Watrin, C., Samba-Louaka, A., and Oswald, E. (2006). Escherichia coli cyclomodulin Cif induces G2 arrest of the host cell cycle without activation of the DNA-damage checkpoint-signalling pathway. Cell Microbiol. 8, 1910-1921. doi: 10.1111/j.1462-5822.2006.00757.x

Teles, R., Teles, F., Frias-Lopez, J., Paster, B., and Haffajee, A. (2013). Lessons learned and unlearned in periodontal microbiology. Periodontol 62, 95-162. doi: $10.1111 /$ prd.12010

Temoin, S., Chakaki, A., Askari, A., El-Halaby, A., Fitzgerald, S., Marcus, R. E., et al. (2012). Identification of oral bacterial DNA in synovial fluid of patients with arthritis with native and failed prosthetic joints. J. Clin. Rheumatol. 18, 117-121. doi: 10.1097/RHU.0b013e3182500c95

Tjalsma, H., Boleij, A., Marchesi, J. R., and Dutilh, B. E. (2012). A bacterial driverpassenger model for colorectal cancer: beyond the usual suspects. Nat. Rev. Microbiol. 10, 575-582. doi: 10.1038/nrmicro2819

Tlaskalova-Hogenova, H., Stepankova, R., Hudcovic, T., Tuckova, L., Cukrowska, B., Lodinova-Zadnikova, R., et al. (2004). Commensal bacteria (normal microflora), mucosal immunity and chronic inflammatory and autoimmune diseases. Immunol. Lett. 93, 97-108. doi: 10.1016/j.imlet.2004.02.005

Tlaskalova-Hogenova, H., Vannucci, L., Klimesova, K., Stepankova, R., Krizan, J., and Kverka, M. (2014). Microbiome and colorectal carcinoma: insights from germ-free and conventional animal models. Cancer J. 20, 217-224. doi: 10.1097/ PPO.0000000000000052

Tomas, I., Diz, P., Tobias, A., Scully, C., and Donos, N. (2012). Periodontal health status and bacteraemia from daily oral activities: systematic review/metaanalysis. J. Clin. Periodontol. 39, 213-228. doi: 10.1111/j.1600-051X.2011. 01784.x

Toprak, N. U., Yagci, A., Gulluoglu, B. M., Akin, M. L., Demirkalem, P., Celenk, T., et al. (2006). A possible role of Bacteroides fragilis enterotoxin in the aetiology of colorectal cancer. Clin. Microbiol. Infect. 12, 782-786. doi: 10.1111/j.1469-0691. 2006.01494.x

Trojanowska, D., Zwolinska-Wcislo, M., Tokarczyk, M., Kosowski, K., Mach, T., and Budak, A. (2010). The role of Candida in inflammatory bowel disease. Estimation of transmission of C. albicans fungi in gastrointestinal tract based on genetic affinity between strains. Med. Sci. Monit. 16, Cr451-Cr457.

Tsoi, H., Chu, E. S. H., Zhang, X., Sheng, J., Nakatsu, G., Ng, S. C., et al. (2017). Peptostreptococcus anaerobius induces intracellular cholesterol biosynthesis in colon cells to induce proliferation and causes dysplasia in mice. Gastroenterology 152, 1419-1433. doi: 10.1053/j.gastro.2017.01.009

Underhill, D. M., and Iliev, I. D. (2014). The mycobiota: interactions between commensal fungi and the host immune system. Nat. Rev. Immunol. 14, 405-416. doi: 10.1038/nri3684

Ungprasert, P., Wijarnpreecha, K., and Wetter, D. A. (2017). Periodontitis and risk of psoriasis: a systematic review and meta-analysis. J. Eur. Acad. Dermatol. Venereol. 31, 857-862. doi: 10.1111/jdv.14051

Urzúa, B., Hermosilla, G., Gamonal, J., Morales-Bozo, I., Canals, M., Barahona, S., et al. (2008). Yeast diversity in the oral microbiota of subjects with periodontitis: Candida albicans and Candida dubliniensis colonize the periodontal pockets. Med. Mycol. 46, 783-793. doi: 10.1080/13693780802060899

Vannucci, L., Stepankova, R., Kozakova, H., Fiserova, A., Rossmann, P., and Tlaskalova-Hogenova, H. (2008). Colorectal carcinogenesis in germ-free and conventionally reared rats: different intestinal environments affect the systemic immunity. Int. J. Oncol. 32, 609-617. doi: 10.3892/ijo.32.3.609

Wade, W. G. (2013). The oral microbiome in health and disease. Pharmacol. Res. 69, 137-143. doi: 10.1016/j.phrs.2012.11.006 
Walker, A. W., Ince, J., Duncan, S. H., Webster, L. M., Holtrop, G., Ze, X., et al. (2011). Dominant and diet-responsive groups of bacteria within the human colonic microbiota. ISME J. 5, 220-230. doi: 10.1038/ismej.2010.118

Wickstrom, C., Davies, J. R., Eriksen, G. V., Veerman, E. C., and Carlstedt, I. (1998). MUC5B is a major gel-forming, oligomeric mucin from human salivary gland, respiratory tract and endocervix: identification of glycoforms and C-terminal cleavage. Biochem. J. 334(Pt 3), 685-693. doi: 10.1042/bj33 40685

Wong, B. K., McGregor, N. R., Butt, H. L., Knight, R., Liu, L. Y., and Darby, I. B. (2016). Association of clinical parameters with periodontal bacterial haemolytic activity. J. Clin. Periodontol. 43, 503-511. doi: 10.1111/jcpe.12554

Wu, G. D., Chen, J., Hoffmann, C., Bittinger, K., Chen, Y. Y., Keilbaugh, S. A., et al. (2011). Linking long-term dietary patterns with gut microbial enterotypes. Science 334, 105-108. doi: 10.1126/science. 1208344

Yamaoka, Y., Suehiro, Y., Hashimoto, S., Hoshida, T., Fujimoto, M., Watanabe, M., et al. (2017). Fusobacterium nucleatum as a prognostic marker of colorectal cancer in a Japanese population. J. Gastroenterol. 53, 517-524. doi: 10.1007/ s00535-017-1382-6

Yu, T. C., Guo, F. F., Yu, Y. N., Sun, T. T., Ma, D., Han, J. X., et al. (2017). Fusobacterium nucleatum promotes chemoresistance to colorectal cancer by modulating autophagy. Cell 170, 548-563. doi: 10.1016/j.cell.2017.07.008 e16, doi: 10.1016/j.cell.2017.07.008

Zanzoni, A., Spinelli, L., Braham, S., and Brun, C. (2017). Perturbed human sub-networks by Fusobacterium nucleatum candidate virulence proteins. Microbiome 5:89. doi: 10.1186/s40168-017-0307-1

Zhou, Y. J., Gao, H. Y., Mihindukulasuriya, K. A., La Rosa, P. S., Wylie, K. M., Vishnivetskaya, T., et al. (2013). Biogeography of the ecosystems of the healthy human body. Genome Biol. 14:R1. doi: 10.1186/Gb-2013-14-1-R1

Conflict of Interest Statement: The authors declare that the research was conducted in the absence of any commercial or financial relationships that could be construed as a potential conflict of interest.

Copyright (c) 2018 Klimesova, Jiraskova Zakostelska and Tlaskalova-Hogenova. This is an open-access article distributed under the terms of the Creative Commons Attribution License (CC BY). The use, distribution or reproduction in other forums is permitted, provided the original author(s) and the copyright owner are credited and that the original publication in this journal is cited, in accordance with accepted academic practice. No use, distribution or reproduction is permitted which does not comply with these terms. 